\title{
"Sotar con vellaco": danza y movimiento en el Libro de buen amor a partir del estudio del léxico
}

\author{
Daniel Rodrigo BENITO SANZ \\ Universidad Complutense de Madrid \\ danibenito82@gmail.com
}

\begin{abstract}
La alegría y el buen humor triunfan en este libro vario, rico, colorido e ingenioso, que parece negarse a brindarnos sus últimos secretos y que entendería en su profunda esencia el público castellano que se congregaba en torno de los juglares que lo recitarían ora con dicción maliciosa, ora con solemnidad doctrinal ${ }^{1} \ldots$
\end{abstract}

\section{RESUMEN}

El presente trabajo propone que el autor del Libro de buen amor conoce y distingue (en ocasiones implícitamente) varias formas de danzar en su tiempo, las circunstancias de su puesta en escena, sus convenciones y su forma de ejecución. Para ello partimos del enfoque tradicional, que identifica y define escenas musicales de danza. Demostramos cómo existe relación entre determinados instrumentos y algunos movimientos de danza, pero también cómo un tercer factor, el de los ambientes, pone en relación instrumentos, sustratos ideológicos y diferentes tipos de baile. Encontramos herramientas tradicionales en la iconografía y el cotejo de algunos textos medievales hispánicos, pero es el análisis de las palabras que indican movimiento la principal innovación de nuestro método frente al de la crítica tradicional. Voces como "sotar", "trotar", "trotalla", "trotera", denotando movimiento descomedido, están mayoritariamente asociadas al juglar, al "vellaco", la "serrana", la "cantadera", el erotismo, la taberna, los dados y ciertos instrumentos, en tanto que es la danza en círculo, más mesurada, la coreografía propia de capas sociales más elevadas, la distintiva de aquellos que tienen normas así para danzar como para amar, la que está relacionada con la alegoría y secundada por un complejo aparato intelectual-filosófico.

Palabras clave: Arcipreste, danza, instrumentos musicales, contextos ideológicos, música, vihuela, Libro de buen amor, rondeau.

${ }^{1}$ M. Riquer (2009), p. 347. 


\begin{abstract}
This article proposes that the author of Libro de buen amor is familiar with and distinguishes (sometimes implicitly) various forms of contemporary dances, and their performance conventions and circumstances. In order to do this we begin by identifying and defining the musical contexts of various dances. We then offer a series of examples that establish relationships between certain musical instruments and specific types of dances and their steps and also address a third factor, namely, how the ideological environment determines the selection of instruments and type of dance. Although considering medieval musical iconography, in this study we focus on the text of the Libro itself, particularly in the work's descriptions of movement and instrumental accompaniment. Words such as "sotar", "trotar", "trotalla", "trotera", that express excessive movement, are mainly associated with the minstrel, the "vellaco", the "serrana", the "cantadera", eroticism, the tavern, dice and certain instruments, while it is the understated circular dance choreography of the higher social class that marks the shared norms of both dance and love that distinguishes their social rank. In the Libro de buen amor allusions to the latter dance form is used allegorically to underscore the nature of the time's passage over the course of the year.
\end{abstract}

Keywords: Archpriest, dance, musical instruments, ideological contexts, music, vihuela, Libro de buen amor, roundel.

Sumario: 1. Introducción, 2. Danza, inmoralidad y erotismo. Los contextos del movimiento descomedido, 2. 1. Las voces "sotar", "trotar" y sus derivados, 2. 2. Una referencia explícita a la danza de movimiento descomedido: el "punto a la trisca", 3. La danza y los instrumentos, 4. Los contextos del movimiento comedido y la danza de los "tres rricos onbres", 5. Conclusiones.

\title{
1. Introducción
}

El propósito de este artículo es demostrar que el autor del Libro de buen amor conoce y distingue varias formas de danzar en su tiempo, los diferentes sustratos ideológicos o intelectual-filosóficos que las contextualizan, las circunstancias de su puesta en escena, los instrumentos que están asociados a ellas y, en alguna medida, su forma de ejecución. Nuestra metodología será el análisis de pasajes del Libro de buen amor $^{2}$ desde el punto de vista del fenómeno de la danza en la obra, a la luz de algunos ejemplos iconográficos y otros textos bajomedievales peninsulares, pero muy especialmente a partir del examen del léxico. Encontraremos que se configuran dos paradigmas en torno a dos formas de danzar. La danza descomedida, con el uso

\footnotetext{
${ }^{2}$ Seguimos, en todo, el texto fijado por Gybbon-Monypenny en la edición que corre a su cargo (GYBBON-MONYPENNY, G. B: Libro de Buen Amor, Madrid, Castalia, 2003). Aunque obviamente nos servimos también del estudio preliminar y notas de otras ediciones del Libro de buen amor, todas las cuadernas y versos que citaremos en adelante están tomadas de la edición de Gybbon-Monypenny. Como es habitual, en nuestras numerosas citas de versos el primer número indica la cuaderna, y la letra el número de verso dentro de ella.
} 
de saltos y acrobacias, es propia de gentes de baja extracción social y aparece constelada de referencias eróticas, en tanto que la nobleza se recrea en bailes comedidos, con normas para danzar así como para amar, revistiendo el gesto físico de un complejo aparato intelectual o alegórico.

En pocas ocasiones una obra literaria surgida en la Castilla medieval suscita el denodado interés de los críticos, alienta la existencia de gran copia de artículos, auspicia la organización de varios congresos internacionales. El Libro de buen amor es obra, por una parte, poliédrica y polisémica, y, por otra, varia e ingeniosa; la cantidad de facetas que ofrece al investigador ha motivado la pluralidad de aproximaciones que son posibles.

A pesar de la gran importancia que el Arcipreste de Hita concede a la música en su obra, el enfoque crítico tradicional estudia sobre todo los instrumentos, pero olvida la amplitud y complejidad del fenómeno musical, un sistema más allá del objeto sonoro (el instrumento). Este enfoque tradicional permanece ajeno a las formas musicales, su relación con el canto y la danza, la puesta en escena en un momento y lugares concretos por parte de músicos prácticos y la propia concepción de la música con que contaba el autor. De igual manera hay que plantearse, creemos, el estudio del uso y significación de los términos de teoría musical de la época. No es más alentadora la falta de bibliografía existente sobre el fenómeno de la danza en el medioevo hispánico, una carencia que no es privativa de la Península.

Felipe Pedrell y Juan José Rey, entre otros, convienen en que el autor del Libro de buen amor $^{3}$ tuvo amplios conocimientos musicales ${ }^{4}$. Han analizado aspectos musicales en la obra Daniel Devoto y David G. Lanoue; Faustino Porras Robles proporciona un estudio organológico sobre los instrumentos en el $L B A^{5}$, en tanto que una de las obras que dan más pautas para el estudio de la música en el $L B A$ es la titulada Poesía juglaresca y juglares, de Ramón Menéndez Pidal ${ }^{6}$. En cuanto al espacio dedicado a la danza medieval, tenemos que tomar en consideración sobre todo los trabajos de Paul Bourcier y Richard Hoppin ${ }^{7}$, historia general de la danza y obra de referencia sobre la música medieval respectivamente, que consagran al menos unas páginas al fenómeno dentro de los largos siglos medievales. Maricarmen Gómez Muntané ${ }^{8}$ ha estudiado algunas danzas religiosas que aparecen en el Llibre Vermell de Montserrat, en tanto que las páginas más útiles para un estudio monográfico sobre la danza medieval, empleando fuentes literarias e históricas hispáni-

\footnotetext{
${ }^{3}$ En adelante $L B A$, en nuestro texto.

${ }^{4}$ Lo hacen en los trabajos siguientes: F. Pedrell (1901), y J. Rey (2002).

${ }^{5}$ Respectivamente, en D. Devoto (1958), pp. 211-222, D. Lanoue (1981) y F. Porras (2008), pp. 113-136.

${ }^{6}$ Vid. R. Menéndez Pidal (1990).

${ }^{7}$ Respectivamente, en P. Bourcier (1994), pp. 50-80, y R. Hoppin (2000), pp. 290-291, $312-$ 316, 356-357, 363-368, 435-446 y 472-474.

${ }^{8}$ M. Gómez Muntané (2001), pp. 265-272.
} 
cas, serían a nuestro juicio las de Ismael Fernández de la Cuesta ${ }^{9}$, incluso a pesar de ser su trabajo una historia general sobre la música medieval hispánica y prehispánica.

Si bien existen muchos estudios que analizan aspectos concretos del fenómeno musical en el $L B A$, no contamos todavía con uno abarcador y sistemático que, en virtud de las muchas perspectivas posibles, esclarezca la concepción de la música que tenía el Arcipreste. Esta aproximación pretende ser la segunda ${ }^{10}$ dentro de una serie de trabajos que aborden, cada uno desde un punto de vista y con diferentes métodos, el estudio del fenómeno musical en el $L B A$, y que vengan a completar este vacío.

Varios críticos han puesto de relieve la importancia de la danza en las sociedades del Occidente medieval europeo, la afición y afinidad de sus gentes con el movimiento corporal rítmico al son de canto y música, con ocasión de algún evento social de relevancia o por simple diversión. Alan Deyermond ha llamado la atención sobre el hecho de que "la manía de danza - una especie de histeria epidémica- era común en el occidente europeo" "1. Efectivamente, debió existir en el Occidente medieval europeo un espacio recurrente, distinguido y variado para la danza; a juzgar por las referencias implícitas y explícitas a la danza que existen en el $L B A$, la Castilla del siglo XIV que conoció el Arcipreste de Hita no debió ser una excepción.

\section{Danza, inmoralidad y erotismo. Los contextos del movimiento descomedido}

Si alguna práctica miraron con recelo las reuniones conciliares, tal como lo demuestran los cánones que se fraguaban en ellas ${ }^{12}$, esta es la danza, y nos importa saber que, al contrario de lo que ocurría con otras prácticas dentro o fuera del culto oficial, el recelo ante la danza fue sistemático ${ }^{13}$. Bien es verdad que existió la danza

\footnotetext{
${ }^{9}$ I. Fernández de la Cuesta (1988), pp. 102-104, 173-176, 325-332 y p. 353.

${ }^{10}$ Existe otro estudio en D.R. Benito Sanz (2012), pp. 279-298.

${ }^{11}$ Sic, en el original. A. Deyermond (1987), p. 338.

${ }^{12}$ Hay que decir con Ismael Fernández de la Cuesta que una "reflexión que podemos hacernos respecto a los gestos y danzas" es que "Todavía a finales del siglo VI, el Concilio III de Toledo nos deja vislumbrar una situación en la que los elementos paganos [...] han vuelto a llenarse de contenido contrario a la moralidad cristiana. Estos son los términos de uno de sus cánones: "Se ha de exterminar por completo la costumbre irreligiosa que el vulgo observa en la celebración de las fiestas de los santos: la gente del pueblo [...] se dedica a bailes y canciones torpes, que no sólo son dañosas para sí mismos, sino también son molestos para los que quieren dedicarse a la religión" (Can. 23)". I. Fernández de la Cuesta (1988), p. 103.

${ }^{13}$ Indica también Ismael Fernández de la Cuesta que "[...] las recriminaciones patrísticas y conciliares se orientan sobre todo a la danza. Canto y danza son objeto de prohibición, principalmente, por dos circunstancias en las que se hallan insertos: la superstición y la obscenidad, vestigios ambos del antiguo paganismo”. I. Fernández de la Cuesta (1988), p. 173.
} 
religiosa ${ }^{14}$ en la Edad Media, relacionada con el culto oficial, pero aun esta fue objeto de controversias, prohibiciones y reglamentaciones. Tratando de asumir el punto de vista de un clérigo medieval que tomara parte en un concilio, tendríamos que concluir que existen en la danza aspectos que pueden considerarse inmorales ${ }^{15}$, y que, por tanto, es necesaria su condena, o al menos su regulación. Tendríamos que concluir también que en la Edad Media la danza era pasatiempo favorito, como aseveran los profesores Richard Hoppin y Alan Deyermond ${ }^{16}$, pero esta tendencia a danzar entró a menudo en conflicto con el ámbito clerical, segunda fuerza contraria en liza, que sometió a la danza a su escrutinio y pugnó por su prohibición o su reglamentación ${ }^{17}$.

Un estudio sistemático del fenómeno de la danza (y la problemática que este genera) entre la gentilidad y los primeros años del Cristianismo merecería un minucioso trabajo aparte. Solo nos importa ahora tener en cuenta que juglares y juglare-

${ }^{14}$ A esta danza religiosa alude Paul Bourcier: "Plusieurs textes rapportent qu'à Sens, le soir de Paques, autour du puits du cloitre, préchantre en tete, les dignitaires du chapitre dansaient, intercalés avec les enfants de choeur. Le P. Claude-François Ménétrier (Des ballets anciens et modernes selon les règles du théatre, 1657, s.1.), note que cette coutume fut générale et prolongée [...]". P. Bourcier (1994), p. 52.

${ }^{15}$ Recoge un testimonio Ismael Fernández de la Cuesta, quien defiende que una "reflexión que podemos hacernos respecto a los gestos y danzas" es que "Todavía a finales del siglo VI, el Concilio III de Toledo nos deja vislumbrar una situación en la que los elementos paganos [...] han vuelto a llenarse de contenido contrario a la moralidad cristiana. Estos son los términos de uno de sus cánones: "Se ha de exterminar por completo la costumbre irreligiosa que el vulgo observa en la celebración de las fiestas de los santos: la gente del pueblo [...] se dedica a bailes y canciones torpes, que no sólo son dañosas para sí mismos, sino también son molestos para los que quieren dedicarse a la religión" (Can. 23)”. I. Fernández de la Cuesta (1988), p. 103.

${ }^{16}$ Richard Hoppin se refiere a "La danza, pasatiempo favorito de la Edad Media [...]". R. Hoppin (2000), p. 365; Alan Deyermond tiene una opinión similar, cuando sostiene que "la manía de danza - una especie de histeria epidémica- era común en el occidente europeo". Sic, en el original. A. Deyermond (1987), p. 338.

${ }^{17} \mathrm{De}$ hecho, tenemos la impresión de que tras una reunión conciliar, la danza se abría paso subrepticiamente incluso en el seno del culto oficial, precisamente por ser "pasatiempo favorito" el movimiento al ritmo del canto y la música, y de que esto ocurría hasta el momento de otra reunión conciliar, en que la danza volvía a ser sometida a reconsideración y escrutinio, para poco a poco volver a repetir aproximadamente el mismo proceso. Nos atrevemos a lanzar esta hipótesis. El afán de reglamentación parece claro en el texto del Llibre Vermell de Montserrat que recoge Maricarmen Gómez Muntané, dado que las danzas religiosas "deben utilizarse honesta y moderadamente para no estorbar a quienes perseveran en oraciones y devotas meditaciones”. M. Gómez Muntané (2001), p. 266. 
$\operatorname{sas}^{18}$ han sido considerados herederos de los mimi e histriones del antiguo Imperio Romano. Pensamos que en buena medida lo fueron, aunque lógicamente evolucionados y adaptados a su tiempo ${ }^{19}$. Gentes de baja extracción social, difícilmente acatarían las pocas amonestaciones conciliares que llegaran a su noticia por mediación de los clérigos, pues perseguían el objetivo de ganarse el sustento mediante el espectáculo $^{20}$. Ciertos elementos de la puesta en escena juglaresca vinculan a estas gentes, profesionales del espectáculo, con los de la gentilidad. Tratemos de analizar algunos.

Ismael Fernández de la Cuesta recoge un valioso texto de San Valerio, oriundo de la provincia de Astorga, en el que hace referencia a un sacerdote llamado Justo ${ }^{21}$, al cual se le atribuye la obscenidad de un profesional de los banquetes o el teatro de la gentilidad. Queremos poner de relieve la referencia a los pies (vid. nota 21), pues veremos que son elemento importante a la hora de atribuir connotaciones eróticas a una danza, y retengamos también en la memoria la alusión a los saltos, marca de deshonestidad y desmesura a los ojos de un clérigo, movimiento este último de que también trataremos. En el texto de la nota ya se alude a una "diabólica sensualidad", relacionada con el tipo concreto de movimiento.

${ }^{18}$ Apunta Ramón Menéndez Pidal que "Muchas de sus artes femeninas derivaban sin duda de las que desplegaron las bailadoras que alegraban los festines romanos, especialmente aquellas muchachas de Cádiz, puellae gaditanae [...]”. R. Menéndez Pidal (1990), p. 61.

19 Pensamos con Ramón Menéndez Pidal que "Los escritores eclesiásticos desde la más remota Edad Media no cesan de usar los términos de la antigüedad clásica: mimi, histriones, thymelici para indicar gentes de su época actual que practicaban espectáculos indecorosos y condenables. Los tres nombres designan tipos procedentes del teatro romano que luego extendieron su acción por las plazas, las calles y las casas para divertir a un público más reducido, o se establecieron en los palacios de los reyes como hombres de placer [...]. Desde el siglo VII aparece en la Europa central, mezclado a los nombres anteriores, algún raro ejemplo de esa nueva denominación: jocularis, usado como sustantivo, o joculator, para designar persona que divertía al rey o al pueblo [...] lo cierto es que el nombre juglar fue el que se vulgarizó en las lenguas modernas en lugar de todos los otros, y como equivalente más o menos exacto de todos los otros”. R. Menéndez Pidal (1990), pp. 29-31.

${ }^{20}$ Indica Ramón Menéndez Pidal que “[...] juglares eran todos los que se ganaban la vida actuando ante un público, para recrearle con la música, o con la literatura, o con charlatanería, o con juegos de manos, de acrobatismo, de mímica, etc". R. Menéndez Pidal (1990), p. 26.

${ }^{21}$ Este documento, en palabras de Ismael Fernández de la Cuesta, "nos relata cómo un sacerdote, llamado Justo, se dedicaba al arte juglar y se hizo célebre frecuentando las casas para amenizar los convites con cantos lascivos [...]. Dice así: Agitábase en un espectáculo público como la virgen obscena en un lujurioso teatro. Y mientras movía los brazos de un lado para otro, juntaba los pies lascivos saltando en derredor en una danza burlona [...] cantaba poemas funestos [...] entregándose así a una diabólica sensualidad”. I. Fernández de la Cuesta (1988), p. 174. 
En la obra literaria del Arcipreste, encontramos la relación que existe entre el "pandero", un instrumento de percusión que puede tener connotaciones eróticas, y la danza de la "cantadera": "desque la cantadera dize el cantar primero,/ sienpre le bullen los pies, e mal para el pandero" (c. 470c y d). Alusión a los pies y su enérgico movimiento que se puede asociar con la danza y con el erotismo, cuando sabemos a continuación que "Texedor e cantadera nunca tienen los pies quedos/ en el telar e en la dança sienpre bullen los dedos" (c. 471a y b) ${ }^{22}$. También útil para desentrañar la relación de la danza con el erotismo en el $L B A$ es la referencia a las "tetas colgadas" (c. 1019a) de la cuarta "serrana", también de baja extracción social, ya que "a todo son de çítola andarían sin ser mostradas" (c. 1019d), es decir, que los pechos de la "serrana" podrían moverse al son de diversos ritmos propios del instrumento y se adaptarían a todos ellos.

El número de danzantes también puede ofrecer una idea de la condición social de estos, sobre el carácter de la danza y sobre su orientación moral. Pues bien, cuando eran dos los juglares, una de las posibilidades era que uno de ellos tocara instrumentos y el otro bailara ${ }^{23}$. De hecho, otro de los elementos importantes que creemos en relación con la danza juglaresca, propia también de cantaderas, infamadas por la inmoralidad que se les presuponía ${ }^{24}$, es el baile individual. Pensamos que, al igual que ocurre con la aparición de los saltos y las acrobacias ${ }^{25}$, la danza en soli-

22 Jacques Joset anota que "los pies le bullen: en sentido literal "no deja de bailar" y, según glosa Correas, pág. 367a: "Búllenle los pies. Está inkieta por dezir o hazer algo." Este algo puede sospecharse gracias al doble sentido de pandero, que, como otros instrumentos de música, alude al sexo, aquí el de la mujer, o al "trasero" [...] sentidos que se traslucen en el refrán de Correas, pág. 460a: "Pandero, el mi pandero, ¿kién os tañerá si io muero? [...] y en los versos indudablemente eróticos de Fuenllana, Libro de música para vihuela, Sevilla, 1554, f. ${ }^{\circ} 134:$ " "no sé qué me bulle / entre las faldas, / que no puedo andar". Interpreto, pues, el segundo hem. con antífrasis irónica: "y sufre el "pandero"”, mejor, creo, que "no deja de ser tocado" (Bl., pág. 77n)". J. Joset (1990), pp. 252-253. La negrita pertenece al texto citado.

${ }^{23}$ Maricarmen Gómez Muntané advierte, en relación a los juglares y juglaresas, sobre diversos puntos en cuanto a su número, sexo y ocupación, aludiendo a la danza individual: "los había que también bailaban, pero ésa fue especialidad más propia de las juglaresas [...] Si los intérpretes eran dos, uno que tocaba y el otro que cantaba - cuando era mujer, lo normal es que bailase -, eran múltiples las opciones, aunque un instrumento de cuerda como acompañante del canto, y en particular la viola, fue siempre lo más corriente". M. Gómez Muntané (2009), pp. 159-160. La cursiva es nuestra. Vid. también nota 21 para apreciar la relación entre la presunta inmoralidad y la danza individual.

${ }^{24}$ Indica Miguel Ángel Ladero Quesada que "Respecto a la juglaresas o "juglaras", había también varias especialidades, más o menos infamadas por la mala condición moral que se les suponía a todas gratuitamente: cantaderas, danzaderas, tocaderas, soldaderas". M. A. Ladero Quesada (2004), p. 126.

${ }^{25}$ Vid. nota 20 sobre las acrobacias mencionadas por Menéndez Pidal. 
tario podía estar relacionada a menudo con la faceta juglaresca de la actuación como medio de subsistencia ${ }^{26}$.

\subsection{Las voces "sotar", "trotar" y sus derivados}

Verbos que indican danza de movimiento enérgico son caracterizadores de tipos populares de baja extracción social en el $L B A$. En la descripción que hace el Arcipreste de la comitiva de juglares (cs. 1227-1234) en las "cuestas e eriales" (c. 1234d), encontramos en la cuaderna 1229 la única aparición de la voz "sota" en el $L B A$ : "la viuela de péndola con aquéstos ý sota" (c. 1229d) ${ }^{27}$. En la cuaderna 1516, el Arcipreste atribuye a los bellacos de ambiente tabernario el movimiento desatado mediante saltos: "çítola, odreçillo, non aman çaguil hallaco;/ más aman la taverna, e sotar con vellaco" (c. 1516c y d). En su encuentro con una de las cuatro serranas, el Arcipreste se atribuye una serie de habilidades de cariz rústico y pastoril (cs. 999-1001). Informa de que es capaz de saltar de cualquier modo; entendemos las palabras del Arcipreste como prestigiadoras de una forma de baile que comprende diversos tipos de salto: "Sé fazer el altibaxo ${ }^{28} /$ e sotar a qual quier muedo" (c. 1001a y b).

Tras un encuentro con otra "serrana", similar al aludido en el ejemplo anterior, el Arcipreste recrea este suceso mediante "[...] tres cantigas, más non pud bien pintalla;/ las dos son chançonetas, la otra de trotalla" (c. 1021 b y c) ${ }^{29}$, sin duda "de trotalla" para adecuar el cariz de la composición a la sierra, a sus moradores, a la forma en que bailan. Por mantener la misma intensidad de movimiento, en la pieza que compone, la "serrana" le dice a continuación "[...] Trota con migo" (c. 1029a). Estamos más ciertos de que el verbo "trotar" alude a la "dança" desarrollada en ciertos ambientes cuando el Arcipreste afirma: "Después fiz muchas cantigas de dança e troteras,/ para judías e moras e para entenderas;/ para en instrumentos de comunales maneras;/ el cantar que non sabes, oylo a cantaderas" (c. 1513). Las

\footnotetext{
${ }^{26}$ Por el contrario, en los bailes en círculo de las cortes, los cuales estudiaremos en el cuarto punto, al ser muy otra la motivación que alienta el baile (la búsqueda de solaz y entretenimiento), o se impone el baile de pareja o son necesarios un mínimo de tres personas para formar un círculo: en el contexto de las danzas cortesanas, no se contempla la actuación de un aristócrata ante un público, para ganarse el sustento, como es lógico. Esto no quiere decir que sistemáticamente una danza individual esté revestida de inmoralidad, pues pensamos que es una tendencia, no una norma.

${ }^{27}$ Efectivamente, "sota", voz relacionada con las palabras con lexema "trot-", como en adelante veremos.

${ }^{28}$ Creemos con Juan José Rey que las voces "altibaxo" y "sotar" son "términos danzarios rústicos". J. J. Rey (2002). Consultado en:

http://cvc.cervantes.es/literatura/arcipreste_hita/01/rey.htm [Consulta: 28/VI/2013].

${ }^{29}$ Para Ismael Fernández de la Cuesta, "Sin duda se trata de una danza coral de ritmo vivo" I. Fernández de la Cuesta (1988), p. 327. Convenimos en la condición del ritmo, a tenor de lo que tratamos de demostrar, pero no sabemos de momento cómo deducir que se trata de una danza "coral".
} 
"cantigas de dança e troteras"30 de nuevo configuran un tipo de paradigma danzario muy vivo, propio de "cantaderas".

En definitiva, podemos concluir que el Arcipreste entreteje un sistema de relaciones en el cual sugiere que, en la Castilla del siglo XIV que conoció, las danzas que se caracterizan por el movimiento descomedido, es decir, que contienen saltos, acrobacias, o que se revisten de connotaciones o referencias eróticas, o que se bailan de forma individual, son propias de gentes de baja extracción social, como juglares, rústicos y serranas, cantaderas y bellacos, quienes pueden danzar en tabernas, calles y plazas, cuestas, eriales y sierras, o bien por entretenimiento o, sobre todo, por ser profesionales del espectáculo, en este último caso para procurarse el sustento actuando ante un público.

\subsection{Una referencia explícita a la danza de movimiento descomedido: el "punto a la trisca"}

Más explícita en tanto que alude a una forma musical ${ }^{31}$ y un tipo concreto de danza, no ya a una forma de movimiento, es la referencia al "corpudo laúd, que tiene punto a la trisca" (c. 1228c); lo que el Arcipreste pretende es relacionar las notas musicales de un instrumento de cuerda pulsada con la enérgica danza pastoril de la "trisca", diciendo que su sonido es apropiado para el carácter de este baile. Se trata de la primera referencia directa en el $L B A$ a una forma musical de danza con nombre específico. La "trisca", como la describe Arturo Tello Ruiz-Pérez, es una danza que pueden bailar tipos sociales rústicos o pastores que nada entienden de la corte, es interpretada con uno o más instrumentos musicales como suplemento del canto (como en este caso) ${ }^{32}$, tiene carácter enérgico y es bailada en línea ${ }^{33}$. Efecti-

\footnotetext{
${ }^{30}$ Analizamos la referencia a la "çítola trotera" (c. 1213d) detalladamente en el tercer punto, dedicado a la danza y los instrumentos.

${ }^{31}$ Utilizamos aquí la expresión "forma musical" en el sentido lato de "tipo concreto de pieza con un nombre específico", ya que en líneas generales no podemos hablar en la Edad Media de "formas musicales" de la misma forma en que lo hacemos hoy. Es decir, que, como indica John Caldwell, "la terminología medieval se refiere a menudo más al tema del poema o al carácter general de las canciones que a su forma propiamente dicha". J. Caldwell (1984), p. 89.

${ }^{32}$ Pensamos que los tres primeros instrumentos que enumera el Arcipreste en la cuaderna 1228 suenan juntos para tocar la trisca, pues al mencionar al tercero sabemos que "la guitarra latina con ésos se aprisca" (c. 1228d). Lo que queremos poner de relieve ahora es que "Lo instrumental como suplemento de lo vocal [...] parece patrimonio de lo rústico" y también lo encontramos ahora, creemos, ya que "Allí sale gritando la guitarra morisca,/ de las bozes aguda e de los puntos arisca" (c. 1228 a y b). Para resaltar que encontramos alusiones al canto y a la música instrumental, la cursiva es nuestra.

${ }^{33}$ Apunta Arturo Tello Ruiz-Pérez que "los pastores y las pastoras bailan la treske al son que marca el canto [...]", y cree significativo que "irrumpan como acompañamiento, una vez más, dos cornes y una musete. Lo instrumental como suplemento de lo vocal, en el sostén de esta danza, parece patrimonio de lo rústico", así como "la algarada pastoril de los
} 
vamente, en relación con esta "algarada pastoril" (vid. nota 33), hay que decir también con Jesús Cañas que la "trisca" guarda relación directa con los "saltos" ${ }^{34}$, de nuevo elemento coreográfico propio de personas de baja extracción social, rústicos o juglares, que ejecutan la danza en un conveniente lugar, ya que sabremos al final de la enumeración juglaresca quién tañe los instrumentos y dónde: "de juglares van llenas cuestas e eriales" (c. 1234d). Ismael Fernández de la Cuesta observa que, según el Arcipreste, el sonido del laúd "era alegre y brillante, propio para la danza de la trisca" ${ }^{35}$ y que "Estas triscas son un tipo de danza que también recogen las Leys d'Amor catalano-occitanas con el nombre de trescas" ${ }^{36}$, muy cercano a la denominación de "trisca"37.

\section{La danza y los instrumentos}

De igual manera que el Arcipreste de Hita amonesta que "Para los instrumentos estar bien acordados,/ a cantares algunos son más apropiados" (c. 1515a y b), asociando ciertos instrumentos a determinados cantares, existen instrumentos que están clara y directamente relacionados con el movimiento físico de carácter enérgico, y por tanto con alguna forma de danza. Si bien esta asociación que seguidamente proponemos no es tan explícita, no es otro el caso de "la çítola trotera" (c. 1213d). Ni la personificación del instrumento ni su asociación con el movimiento vivo parecen invención de Juan Ruiz, si tenemos en cuenta que en la Castilla bajomedieval el autor del Libro de Alexandre, sea quien fuere, ya se había referido a la "çitola que

danzantes, ahora en línea" en definitiva, "la tresche parece implicar siempre un acompañamiento instrumental y, en lo social, una danza lúdica en la que pueden tomar parte personas fuera del estamento nobiliario de la cortesía". A. Tello Ruiz-Pérez (2008), p. 10. Ha anotado también más someramente Alberto Blecua en su edición del $L B A$ que "La trisca es una danza rústica". A. Blecua (2010), p. 306. Vid. nota al verso 1228c, en su edición.

${ }^{34} \mathrm{~J}$. Cañas (2007), p. 664.

${ }^{35}$ I. Fernández de la Cuesta (1988), p. 353.

${ }^{36}$ I. Fernández de la Cuesta (1988), p. 327. Para entender la presencia de esta danza en las Leys d'Amor, obra bastante culta, hay que pensar con Arturo Tello Ruiz-Pérez que no existe una línea divisoria definitiva entre lo popular y lo culto en lo referente a algunos tipos de danza y sus correspondientes contextos, pues "el elemento distintivo más relevante entre la tresche y la carole no radica en la disposición en línea o en círculo de los participantes" y, por otra parte, "Es lógico pensar que igual que los nobles se deleitaban participando del baile con pastores y campesinos, éstos a la inversa imitasen de algún modo la danza de la cortesía"; en definitiva, "el punto real de ruptura entre ambas danzas es de esencia filosófica". A. Tello Ruiz-Pérez (2008), p. 11.

${ }^{37}$ Existen otras alusiones a esta danza en la Castilla bajomedieval, en una obra anterior a la del Arcipreste, en el Libro de Alexandre, asimismo en un contexto festivo y también en campo abierto, pues cuando "El mes era de mayo, un tiempo glorïoso" (c. 1950a), encontramos que "fazen las dueñas triscas en camisas delgadas" (c. 1952c). J. Cañas (2007), pp. 466-467. 
más trota" ${ }^{38}$. No consideramos casual en el texto del Arcipreste la coincidencia del lexema "trot-" y la cítola, con su correspondiente personificación, que propone considerar al propio instrumento moviéndose, es decir, reflejando en sí mismo el efecto de la música que produce. Más útil para desentrañar la relación de la danza con los instrumentos es la referencia a las "tetas colgadas" (c. 1019a) de la cuarta "serrana" que encuentra el Arcipreste, ya que "a todo son de çítola andarían sin ser mostradas" (c. 1019d). Juan Ruiz está relacionando sin embargo al instrumento con diversos sones o formas musicales ${ }^{39}$, seguramente con diversos ritmos, cuando dice que las "tetas" se adaptarían a todos ellos. De igual manera, "çítola, odreçillo, non aman çaguil hallaco;/ más aman la taverna, e sotar con vellaco" (cs. 1516c y d), es decir, que tanto la "çítola" como el "odreçillo" no solamente son instrumentos que tienen la "taverna", a la que "aman", como uno de sus marcos apropiados, sino que están relacionados con el movimiento enérgico que expresa el verbo "sotar", movimiento que ejecutan inclusive ellos mismos, al estar personificados. Tanto "çítola" como "odreçillo" cumplen la condición de ser instrumentos melódicos, apropiados para la monodia profana ${ }^{40}$.

Al igual que la "çítola", vemos que "la viuela de péndola" junto a otros instrumentos también "sota" (c. 1229d). Encontramos de nuevo la atribución de cualidades inapropiadas para un instrumento, como es la capacidad de saltar ${ }^{41}$, pero más importante es poner de relieve la insistencia del Arcipreste en relacionar verbos de movimiento enérgico con instrumentos cordófonos pulsados, como es el caso de esta vihuela, tañida con una "péndola" (1229d), es decir, un tipo de péñola o plectro. Recordemos que la "çítola trotera" (c. 1213d) era también un cordófono pulsado, es decir, un instrumento de cuerda en el que es necesario tañer varias notas diferenciadas por cada unidad de tiempo, si es que se ha de tocar una danza, al no ser un instrumento que puede producir sonido de forma más continua, como es el caso de

38 J. Cañas (2007), p. 406. Menéndez Pidal ya propuso la comparación, tomando los dos textos, de sintagmas con adjetivos que contienen el lexema "trot-". R. Menéndez Pidal (1990), p. 75.

39 A propósito de las supuestas "formas musicales" en la Edad Media, pensamos con John Caldwell que "la terminología medieval se refiere a menudo más al tema del poema o al carácter general de las canciones que a su forma propiamente dicha". J. Caldwell (1984), p. 89

${ }^{40}$ La monodia profana, la música que no pertenecía al culto oficial bajomedieval, la propia de juglares y trovadores: "La música, a una voz como toda la del repertorio trovadoresco...”. M. Gómez Muntané (2009), pp. 153-154. Es menos importante (pero quizá útil para desentrañar el sistema de relaciones que el texto establece entre ciertos instrumentos y la danza) el hecho de poder pensar en una intercambiabilidad, por tanto, de "sotar" y "trotar", establecida implícitamente, si tenemos en cuenta la mencionada referencia a "la çítola trotera" (c. 1213d), cordófono pulsado que también prefiere "sotar" (c. 1516d).

${ }^{41}$ Quizá cabe pensar, en los tres casos, que si la "çítola e odreçillo" y la "viuela de péndola" son tan apropiados para la danza que inclusive los mismos instrumentos bailan, qué no les ocurrirá a los que se deleiten en la taberna, en la sierra o en los caminos con su son. 
su homónima tocada con arco, la "viuela de arco" (1231a), de cuerda frotada, por tanto. Mucho más explícita en cuanto a interpretación musical es la referencia al "corpudo laúd, que tiene punto a la trisca" (c. 1228c), es decir, que las notas musicales que pueden obtenerse del cordófono pulsado son apropiadas para la enérgica danza pastoril de la trisca. Se trata de la primera referencia en el $L B A$ a una forma musical de danza como es la "trisca", pero no la única a un cordófono pulsado relacionado con el movimiento enérgico de danza, como arriba dijimos ${ }^{42}$.

Por último, nos referiremos a la relación que existe en el $L B A$ entre el "pandero", un instrumento de percusión, y la danza, ya que "desque la cantadera dize el cantar primero,/ sienpre le bullen los pies, e mal para el pandero" (c. 470c y d). Movimiento de pies que se puede asociar con la danza, pues a continuación dirá que "Texedor e cantadera nunca tienen los pies quedos/ en el telar e en la dança sienpre bullen los dedos" (c. 471a y b). Llama la atención la relación existente entre los instrumentos de percusión como este "pandero" u otro tipo de instrumento de percusión y la mujer que canta y baila ${ }^{43}$, si observamos varias miniaturas del Cancioneiro da Ajuda ${ }^{44}$ (en dos de ellas se ha identificado a una muchacha con pandero; son las que indicamos en nota).

\section{Los contextos del movimiento comedido y la danza de los "tres rricos onbres"}

No todas las alusiones a la danza que propone el Arcipreste con mayor o menor grado de explicitud son propias de tipos populares de baja extracción social, como no todas son ejecutadas mediante saltos, ejercicios gimnásticos ni acrobatismo, en ambientes tabernarios y rústicos. Existían efectivamente en la Castilla bajomedieval del Arcipreste otras danzas que este debió conocer. En ellas, otro tipo de danzantes,

${ }^{42}$ Esta condición organológica, la producción de sonido mediante cuerdas pulsadas, y su proximidad con el movimiento vivo de danza la comparten en el $L B A$ la "çítola", en las tres menciones que hace el Arcipreste, la "viuela de péndola" y el "laúd", estos últimos mencionados solo una vez.

${ }^{43}$ Menéndez Pidal advierte, en las miniaturas del Cancioneiro da Ajuda, que "De las 16 miniaturas del Cancioneiro únicamente cuatro dibujan al juglar solo o acompañado de otro juglar o de un muchacho cantor; las doce restantes, al lado del juglar que toca, ponen la cantadora. Ésta, las más veces, toca unas castañuelas en forma de tejoletas planas, canta y baila con los brazos en alto [...] en tres miniaturas la cantadora toca el pandero...". R. Menéndez Pidal (1990), pp. 63-64. La cursiva es nuestra; se trata de otro testimonio del medioevo peninsular en que existe relación entre la mujer, la percusión y la danza.

${ }^{44}$ Cancioneiro da Ajuda, Lisboa, Biblioteca do Palácio Real da Ajuda, f. 21r. Consultado en Cantigas Medievais Galego-Portuguesas, Universidade Nova de Lisboa (UNL): http://cantigas.fcsh.unl.pt/iluminura.asp?img=A_119_21 [Consulta: 28/VI/2013]. "Nobre, jogral com viola de arco, rapariga com pandeiro redondo e de soalhas exteriores".

Ibidem, f. 60r. http://cantigas.fcsh.unl.pt/iluminura.asp?img=A_197_60 [Consulta: 28/VI/2013]. "Nobre, jogral com cítola, rapariga com pandeiro redondo com soalhas exteriores". 
pertenecientes a las capas más altas de la sociedad e imbuidos por tanto de un importante aparato "intelectual y filosófico"45, desarrollaban más refinadas y reglamentadas coreografías en las cortes y los jardines de recreo ${ }^{46}$. Seguramente no era del todo necesaria la música instrumental como complemento de lo vocal en los pasatiempos de este colectivo ${ }^{47}$, que no contemplaba la idea de ganarse la vida bailando o actuando ante un público, sino de buscar solaz y entretenimiento, dada su condición acomodada en la corte ${ }^{48}$. Las coreografías revestirían mayor o menor grado de complicación, pero en cualquier caso responderían a un modelo reglamentado, a unas normas existentes para bailar, así como para componer y amar ${ }^{49}$. Lo que es seguro es que una de las figuras frecuentes que debieron formar los danzantes es el círculo, y el elemento vocal tenía preponderancia sobre el instrumental ${ }^{50}$. Estas danzas en círculo, denominadas "carole" o "rondeau", eran danzas cortesanas

${ }^{45}$ Arturo Tello, a propósito del Roman de la Rose, llama la atención sobre "el canto y la danza, como perentorios aderezos otorgados por la cortesía. Por tópica y convencional que pueda parecer esta dinámica $-\mathrm{y}$ de hecho lo es- en la que Guillaume de Lorris hace acopio de un número razonablemente limitado de términos, lo cierto es que viene a compendiar el proceder habitual de la chanson courtoise en un sistema tradicional de temas y registros poéticos basado en una economía de medios de corte, por así decir, intelectual y filosófico". A. Tello Ruiz-Pérez (2008), p. 2.

${ }^{46}$ Pone de relieve el mismo Arturo Tello, al comienzo de su artículo sobre la danza cortesana desarrollada en el territorio de la actual Francia, que esta tiene lugar en "El esplendor del jardín de Recreo, en el que la belleza se erige como medida de la naturaleza". A. Tello RuizPérez (2008), p. 1.

${ }^{47}$ Observa Arturo Tello que "los pastores y las pastoras bailan la treske al son que marca el canto [...]", y cree significativo que "irrumpan como acompañamiento, una vez más, dos cornes y una musete. Lo instrumental como suplemento de lo vocal, en el sostén de esta danza, parece patrimonio de lo rústico", así como "la algarada pastoril de los danzantes, ahora en línea" en definitiva, "la tresche parece implicar siempre un acompañamiento instrumental $\mathrm{y}$, en lo social, una danza lúdica en la que pueden tomar parte personas fuera del estamento nobiliario de la cortesía". A. Tello Ruiz-Pérez (2008), p. 10.

${ }^{48}$ Este fenómeno cortesano "se inserta dentro de un fenómeno generalizado en las casas feudales del sur de Francia: el del aumento del nivel de vida [...] en una sociedad constituida por guerreros aristócratas [...]. Las costumbres de los nobles se fueron refinando al tiempo que descubrían el lujo [...] y ello hizo aparecer una forma de comportamiento a la que se ha dado en llamar "ideal cortés". Su vehículo de expresión más sutil fue la poesía, que trata del fin'amor, un reflejo de los códigos amorosos de comportamiento del caballero para con su dama". M. Gómez Muntané (2009), p. 144.

${ }^{49}$ Por contraste con personas de baja extracción social, este colectivo se caracteriza por "amar lealmente gracias al amor; algo no muy acorde sin duda con el espíritu imperante en las fiestas de mayo pastoriles". A. Tello Ruiz-Pérez (2008), p. 16.

50 "En el Norte de Francia, carole y ronde [...], han sido términos más o menos sinónimos que designaban danzas en círculo en las que se alternaba la interpretación del grupo de los estribillos con los versos cantados por el que dirigía la danza". R. Hoppin (2000), p. 313. 
cuyo origen podemos encontrarlo en la zona geográfica de la actual Francia. En esta zona, "En el norte, como en el sur, la poesía y la canción lírica comenzaron como un arte aristocrático [...] fueron las cortes de la nobleza las que procuraron a esos hombres patronazgo y audiencia para sus canciones" $"$.

Volviendo a la obra literaria que nos ocupa, encontramos un pasaje en que el Arcipreste describe la tienda de su "señor don Amor" (c. 1263c), muy ricamente constituida, como no podría ser de otra manera a tenor del tipo concreto de danza y de cuanta maravilla iba a presenciar en su interior: "Desque ovo yantado, fue la tienda armada:/ nunca pudo ver omne cosa tan acabada;/ bien creo que de ángeles fue tal cosa obrada,/ que omne terrenal desto non faría nada" (c. 1265). Una vez dentro, presencia la siguiente escena protagonizada por tres nobles: "Andan tres rricos onbres allí en una dança:/ entre uno e otro non cabe punta de lança;/ del primero al segundo ay una grand labrança;/ el segundo al terçero con cosa non le alcança" (c. 1287). La coreografía reviste tal complejidad esta vez que supone una paradoja: entre uno y otro no cabe una punta de lanza, pero de uno a otro hay gran espacio y el segundo nunca alcanza al tercero. Pensamos que el Arcipreste debe referirse a una danza cortesana en círculo, ya que se trata de tres nobles que no llegan a alcanzarse. No se trata de cualquier clase de noble, sino de "tres rricos onbres", de la más alta nobleza, cuya existencia debió conocer el Arcipreste en la Castilla del siglo $\mathrm{XIV}^{52}$. Lo que es cierto, pensamos, además de la elevadísima extracción social de los tres danzantes, es que existe de nuevo, y cuando menos, un importante aparato intelectual y filosófico que contextualiza esta danza, pues sabremos más adelante que "los omnes son los meses" (c. 1300c), pues la cuaderna nos indica que "El tablero, la tabla, la dança, la carrera,/ son quatro tenporadas del año del espera; los omnes son los meses, cosa es verdadera;/ andan e non se alcançan, atienden se en rribera" (c. 1300), así pues, la danza es una estación del año, los nobles son tres de los meses, configurando una compleja alegoría, y completamos la coreografía sabiendo que los tres "rricos onbres" avanzan pero no se alcanzan nunca, sino que se esperan, otro argumento para determinar que el Arcipreste debió pensar en una danza en círculo. También nos aleja de los ambientes rústicos y tabernarios el hecho de

${ }^{51}$ R. Hoppin (2000), p. 302.

52 "La población rural siguió siendo mayoritaria en la sociedad castellana de los últimos siglos medievales. Cabe distinguir en ella cuatro grupos: ricos hombres, hidalgos, labradores o abarqueros y collazos. El grupo de los ricos hombres, muy reducido, constituyó el escalón más elevado de la nobleza feudal y era poseedor de extensos patrimonios a la vez que desempeñaba cargos importantes en la corte. A este grupo pertenecían los Guevara, los Hurtado, los Mendoza, los Pérez de Ayala, los Velasco, etc., que en la segunda mitad del siglo XIV pasaron a formar la "nobleza nueva" gracias a las mercedes que les otorgó el primer monarca Trastámara (desde 1369), se incorporaron a las actividades comerciales (exportación de lanas) y se beneficiaron de alcabalas, portazgos y diezmos señoriales". M. Riu Riu (1989), p. 447. 
que la danza se celebra en la misma tienda de un emperador, pues sabemos que "Estos dos enperadores Amor e Carnal eran" (c. 1211a).

Tanto el lugar en que tiene lugar la danza como las personas que la ejecutan, el contexto ideológico y alegórico en que se inscribe y la presumible complejidad de la coreografía, descrita mediante una paradoja, así como la ausencia de instrumentos $^{53}$, nos sitúan en el polo opuesto a los saltos y el movimiento descomedido, propios de las gentes de baja extracción social.

Encontramos en la iconografía de la Castilla bajomedieval otro ejemplo de baile cortesano en círculo, con tres personas que se toman las manos. En la misma Corte del Rey Alfonso X, es el caso de la danza representada en la miniatura de la Cantiga 120 en las Cantigas de Santa María: En el centro de la composición, vemos un violero con una espléndida vihuela de arco, instrumento de enorme importancia ${ }^{54}$. A ambos lados del Rey Sabio, quien quizá amonesta indicando con el índice a quién debe estar dedicada la música y la danza, otros instrumentistas consagran su música a la Virgen ${ }^{55}$.

\section{Conclusiones}

A juzgar por la cantidad de referencias implícitas y explícitas que existen en el $L B A$ en relación con la danza, debió existir un lugar destacado para ella, en contextos variados; el Arcipreste de Hita retrata, en ocasiones quizá de forma inconsciente, escenas de danza de la Castilla del siglo XIV que conoció. En el caso de la danza descomedida, propia de gentes de baja extracción social, el Arcipreste entreteje un sistema de relaciones en el cual sugiere que las danzas que se caracterizan por el movimiento descomedido, es decir, que contienen saltos, acrobacias, o que se revisten de connotaciones o referencias eróticas, o que se bailan de forma individual, son propias de gentes de baja extracción social, como juglares, rústicos y serranas, cantaderas y bellacos, quienes pueden danzar en tabernas, calles y plazas, cuestas, eriales y sierras, o bien por entretenimiento o sobre todo por ser profesionales del espectáculo, en este último caso para procurarse el sustento actuando ante un público. En cambio, en el caso de la danza cortesana, tanto el lugar en que tiene lugar la danza como la extracción social de las personas que la ejecutan y su número, el aparato intelectual y alegórico que la enmarca y la presumible complejidad de la

\footnotetext{
53 "Lo instrumental como suplemento de lo vocal [...] parece patrimonio de lo rústico". A. Tello Ruiz-Pérez (2008), p. 10.

${ }^{54}$ En D.R. Benito Sanz (2012), puede verse el segundo punto sobre la jerarquía instrumental.

${ }^{55}$ Cantigas de Santa María, El Escorial, Real Biblioteca del Monasterio de San Lorenzo de El Escorial, MS j.b.2. La miniatura puede verse en H. Anglés (1943-64), facsímil y transcripción completa del MS j.b.2 de El Escorial, f. 170v. Cantiga 120. En fuentes literarias, el poeta castellano Gonzalo de Berceo hace alusión a las "grandes quirolas", es decir, danzas en círculo, las cuales debió observar en la Castilla bajomedieval que conoció. M. Gerli (1995), p. 187.
} 
coreografía, descrita mediante una paradoja, así como la ausencia de instrumentos, nos sitúan en un plano opuesto al movimiento descomedido de rústicos y juglares.

Pensamos que a la carencia de monografías y la falta de fuentes hay que enfrentar, como primer paso, una reflexión sobre las herramientas para el estudio de la danza, y su adecuada utilización ${ }^{56}$, dos apartados sobre los que el presente trabajo pretende llamar la atención. Hemos observado la importancia del estudio de las referencias implícitas a la danza, es decir, el análisis de las palabras que indican movimiento, en todas sus implicaciones y a varios niveles. Creemos que con este método podemos formarnos una idea más precisa de un fenómeno que adolece de un vacío en los estudios medievales, en comparación con otros campos. La iconografía representa un momento escogido, significativo, representativo para el miniaturista experto, y por tanto puede ayudar a desentrañar el aspecto clave de una coreografía o de su contexto intelectual y filosófico. Es, en este sentido, más esclarecedora que una secuencia de vídeo, en la que no se jerarquiza en función de unos elementos clave.

Una vez llevada a cabo la revisión de las fuentes y su forma de tratamiento, hay que observar que, a la hora de abordar un estudio sobre cualquier danza, es mucho más importante dilucidar, a nuestro juicio, en qué contexto ideológico y aparato intelectual-filosófico (si lo hay) se inscribe, e incluso determinar el carácter general de la danza, que desentrañar todos los pasos de la coreografía. La imposibilidad lógica de conseguir esto último, en un estudio sobre danzas del pasado, no debe ser un factor determinante a la hora de confeccionar (o no confeccionar) estudios sobre la danza. Mientras tanto, continúan guardando los mayores secretos de su puesta en escena y su contexto ideológico las escenas de danza a las que alude el Arcipreste ${ }^{57}$.

\section{OBRAS CITADAS}

ANGLÉS, Higinio: La música de las Cantigas de Santa María del Rey Alfonso el

Sabio, 3 vols, Barcelona, Diputación provincial de Barcelona: Biblioteca central, 1943-64.

\footnotetext{
${ }^{56}$ La adecuada utilización implica, cuando se emplea iconografía musical tomada de manuscritos, citar el manuscrito, el lugar en el que se encuentra, el número de folio y la indicación de "recto" o "verso", según corresponda. Un principio tan lógico y tan básico ayudaría a la comunicación entre investigadores y a la localización de fuentes.

${ }^{57}$ El presente trabajo simplemente no habría sido posible sin la ayuda, la paciencia y las sugerencias de los profesores Álvaro Alonso Miguel, Arturo Tello Ruiz-Pérez, Carmen Julia Gutiérrez, Cristina Bordas Ibáñez, Víctor de Lama y Ángel Gómez Moreno, y de los musicólogos Matías Company Casas, Mariángeles Vizán, Pablo Zamarrón Yuste y Ana Gema Zúmel Llorente, quien vivió todo el proceso.
} 
BENITO SANZ, Daniel Rodrigo: ““'Allí sale gritando la guitarra morisca”: Nueva aproximación a una enumeración de instrumentos en el Libro de buen amor", Dicenda. Cuadernos de Filología Hispánica, Vol. 30 (2012), pp. 279-298.

BLECUA, Alberto: Libro de buen amor, Madrid, Cátedra, 2010.

BOURCIER, Paul: Histoire de la Danse en Occident, Tours, Éditions du Seuil, 1994.

CALDWELL, John: La música medieval, Madrid, Alianza Música, 1984.

CAÑAS, Jesús: Libro de Alexandre, Madrid, Cátedra, 2007.

DDvoto, Daniel: "La enumeración de instrumentos musicales en la poesía medieval castellana", en Miscelánea en homenaje a Monseñor Higinio Anglés, I, Barcelona, Consejo Superior de Investigaciones Científicas, 1958, pp. 211-222.

DEYERMOND, Alan: Historia de la literatura española 1. La Edad Media, Barcelona, Editorial Ariel, 1987.

FERNÁNDEZ DE LA CUESTA, Ismael: Historia de la música española 1. Desde los orígenes hasta el "ars nova", Madrid, Alianza Música, 1988.

GERLI, Michael: Gonzalo de Berceo. Milagros de Nuestra Señora, Madrid, Cátedra, 1995.

GÓMEZ MunTANÉ, Maricarmen: La música medieval en España, Kassel, Edition Reichenberger, 2001.

GÓMEZ MUNTANÉ, Maricarmen: Historia de la música en España e Hispanoamérica, Vol. 1, Madrid, Fondo de Cultura Económica de España, 2009.

GYBBON-MONYPENNY, G.B: Libro de buen amor, Madrid, Castalia, 2003.

HopPIN, Richard: La música medieval, Madrid, Akal Música, 2000.

JOSET, Jacques: Libro de buen amor, Madrid, Taurus, 1990.

LADERO QUESADA, Miguel Ángel: Las fiestas en la cultura medieval, Barcelona, Random House Mondadori, 2004.

Lanoue, David G: Musical Imagery in the Poetry of Juan Ruiz, Universidad de Nebraska, 1981.

MENÉNDEZ PIDAL, Ramón: Poesía juglaresca y juglares. Orígenes de las literaturas románicas, Madrid, Espasa-Calpe, 1990.

PEDRELL, Felipe: Emporio científico e histórico de organografía musical antigua española, Barcelona, Manuales enciclopédicos Gili, 1901.

PORRAS ROBLES, Faustino: "Los instrumentos musicales en la poesía castellana medieval. Enumeración y descripción organológica", Lemir, 12 (2008), pp. 113136.

REY, Juan José: "Puntos y notas al músico Juan Ruiz", en Juan Ruiz, Arcipreste de Hita, y el "Libro de buen amor", I Congreso Internacional, Alcalá la Real, Centro Virtual Cervantes, Instituto Cervantes, 2002. Consultado en: http://cvc.cervantes.es/literatura/arcipreste_hita/01/rey.htm [Consulta: $1 / 09 / 2012]$.

RIQUER, Martín de: Historia de la literatura universal, Vol. 1, Barcelona, RBA, 2009.

RIU RIU, Manuel: Edad Media (711-1500), Vol. 2, Madrid, Espasa-Calpe, 1989. 
TELlo RUIZ-PÉREZ, Arturo: "La mirada, la voz y el corazón: notas sobre las alusiones directas a la danza en la lírica d'oül de los siglos XII y XIII", en Delantera de Paraíso. Estudios en homenaje a Luis G. Iberni, eds. Celsa Alonso, Carmen Julia GuTIÉRREZ y Javier SUÁREZ-PAJARES, Madrid: ICCMU, 2008, pp. 531556.

\section{MANUSCRITOS}

Cancioneiro da Ajuda, Lisboa, Biblioteca do Palácio Real da Ajuda (P-La).

Cantigas de Santa María, El Escorial, Real Biblioteca del Monasterio de San Lorenzo de El Escorial, MS j.b.2. 